\title{
Impact of Social Media on Consumer Buying Behaviour of Organic Food Products in Tamil Nadu
}

\author{
Ms. U.Gayathri ${ }^{1}$, Dr.P.Poongodi ${ }^{2}$ \\ Research Scholar (Ph. D), Department of Management, \\ Kongu Arts and Science College (Autonomous), Erode-638107, Tamil Nadu ${ }^{1}$ \\ Professor, Department of Business Administration with Computer Application, \\ Kongu Arts and Science College (Autonomous), Erode-638107, Tamil Nadu ${ }^{2}$
}

\begin{abstract}
The pandemic caused by COVID-19 has changed the mindset of many consumers. They are increasingly aware of the risks of not caring for the planet. Before the pandemic, there was a perceived increase in collective environmental concern and sustainability, but COVID-19 has further accelerated this process and motivated more people to assume this responsibility. Thus, the health crisis could trigger the consumption of organic foods, which are foods produced through environmentally friendly agricultural methods and that have not been artificially altered. It is essential for retailers to know how these consumers of organic foods behave in order to try to modify their strategies. In using of Social websites by consumers has mainly increased and usages of Social Networking Websites have wide effect on these consumers in various ways. There are many online networking sites which affect consumer behavior. Social websites like Facebook, Twitter, Instagram, YouTube etc. is having many features which affect and attract many numbers of people. In todays life Social Media become a very strong useful tool using by the consumer in buying decisions. To investigate the consumer's decision making process for organic food products by empirically extending the theory of planned behavior for the organic food products consumption in India. The results of a survey administered a survey to a sample of 195 consumers show that trust is influenced by satisfaction and attitude. In relation to the behavioural variables, satisfaction is the variable that has the greatest influence on purchase intentions and WOM intentions.
\end{abstract}

Keywords: Social media, consumer buying behaviour, Organic food products.

\section{INTRODUCTION}

Organic food is a broadly defined as category of plants or animal products, which are grown without conventional chemical fertilizers and pesticides, growth hormones, antibiotics or genetically modified organisms. It is grown naturally with an ethically, environmentally, and socially responsible approach (Agricultural and Processed Food Products Exports Development Authority) (APEDA, 2018, March 31); (Paul and Rana, 2012); (Hill and Lynchehaun 2002); (Davies, Titterington, nad Cochrane, 1995). Organic food consumption is often associated to an alternative lifestyle, which includes active environmentalism, vegetarianism, and/or alternative medicine (Cicia, Giudice, and Scarpa, 2002). Over the last decade, the organic food sector has been one of the fastest growing segments in the global food market. Global market for organic produce have increased five times since 1999 (McCarthy, 2015).

A study is made of the social media of buying behaviour process of consumers for complex purchases, with a special emphasis on how this process is influenced by possible use of social media. Complex buying behaviour in this context refers to costly frequent purchases with high consumer involvement, significant brand differences, and high risk. Social media is a relatively recent phenomenon. Over the last decade, the World Wide Web has seen a proliferation of userdriven web technologies such as blogs, social networks and media sharing platforms. Social media modifies the communication methods between sellers and buyers. E commerce influences the consumers in their purchase decision. Communication through social media is a new platform to exchange information about product and services. The analysis of consumer behaviour is the core activity for selling product and service since most consumers are using the internet and on-line social media tools. Social media become an important media to introduce and market products and also to do surveys. Nowadays Social media is an important marketing tool for promotional activities. Hence it becomes necessary to perceive how Social media is affecting consumer behaviour. 


\section{International Advanced Research Journal in Science, Engineering and Technology}

Vol. 8, Issue 6, June 2021

DOI: $10.17148 /$ IARJSET.2021.8619

\section{Concept of Social Media}

Social media, in one form or another form has been presence since the 1970s. The look and feel has modified greatly since the early days, the communication concept remains the same. Today technology permits for a larger interaction and period of communication however similar to its roots; social media allows people to broadcast to the lots. It is a method by using social media site to attain the attention of people. These programs concentrate on developing a content which will attract the attention of the readers in social media and make them to share the contents in their social networking site.Many new social networking sites came into existence with many advances options for the users to maintain friend list and to communicate with friends. In 2004, face book, the largest \& most popular social networking website was launched. The platform has been integral in bringing social media into the thought and nowadays sees over millions of active users. Twitter was launched in 2006 and is a popular micro-blogging website. Social media is not just restricted alone, it includes sending photos, multimedia message contents etc. With the growth of social media, the social media websites started concentrating on developing technology for sharing of information in various forms like photos, audio and video. In 2005, YouTube was launched which was the first and foremost video sharing and hosting site, caused an entire new way of exchanging of information in the world

Various social media specialists define the term Social Media and their definitions on the various points:

- $\quad$ An on-line medium powered by the internet for social communication.

- A two-way communication medium.

- A medium that permits creation and exchange of information.

- A medium that is supported by web technology services.

- $\quad$ Are platforms like Twitter, Facebook, Instagram, Youtube, Social Gaming, Blogs, Social Bookmarking, etc.

\section{Consumer Behaviour}

Consumer buying behavior is the study of how individuals and organizations select and use products and services. This primarily focuses on psychology, motivations, and behaviors, such as how people choose between brands, how they research and shop, and how marketing campaigns can be improved so brands can effectively influence them. Personal, psychological, and social factors influence the consumer behavior. Personal factors deal with an individuals interests and opinions, which are affected by their demographics. Psychological factors are based on their perceptions and attitudes, including their ability to comprehend information and how they see their needs. Finally, social factors are made up of ones peer groups, socioeconomic classes, and even social media influence.

\section{STAGES IN CONSUMER BUYING PROCESS}

1.Need Recognition: This stage is where the consumers realize that they need something and that making a purchase will address the need. For businesses, this is an opportunity to use other marketing strategies to help prospects recognize a need or re-evaluate an existing one.

2.Information Search: At this stage, prospects are looking for more information about the product they want to purchase. This is where product reviews, websites, blog posts, and search ads can come in handy.

3.Evaluation of Alternatives: Given that many different products could address their needs, consumers often use evaluative criteria based on their priorities. At this stage, the marketing strategies should be aiming to convince prospects that their criteria match the products strengths.

4.Purchase Decision: The consumer has looked at multiple items and compared them based on their evaluative criteria. This is the stage where the consumer has decided to make the purchase.

5.Post Purchase Behaviour: The Buying Process doesnt end at the sale. The customers experience with the product would dictate if they were satisfied by the purchase or not. On the basis of being either satisfied or dissatisfied, it is common for customers to distribte their positive or negative feedback about the product. This may be through reviews on website, social media networks or word of mouth.

\section{SOCIAL MEDIA \& CONSUMER BEHAVIOUR: CHALLENGES \& DEVELOPMENT}

When creating a purchase decision, social media influence take part a necessary role. When a customer decided to purchase, then he prepares a list of options for deciding the proper product. Even though e-commerce sites are offering various tools for browsing, searching for the product, proving product specifications, it is continuous to be a difficult task for the customer. Individuals are looking for reviews, recommendations and ranking from the existing customers and from trusted people which includes workers in the organizations, members from family, relatives and friends. Social media sites provides quick access to the friends, relatives and trusted people through web and also permits the customer to view and access to the posts and comments in an easier way. This technique helps the consumer to know about the product information shared and posted by others in social media. 


\section{International Advanced Research Journal in Science, Engineering and Technology}

Vol. 8, Issue 6, June 2021

DOI: $10.17148 /$ IARJSET.2021.8619

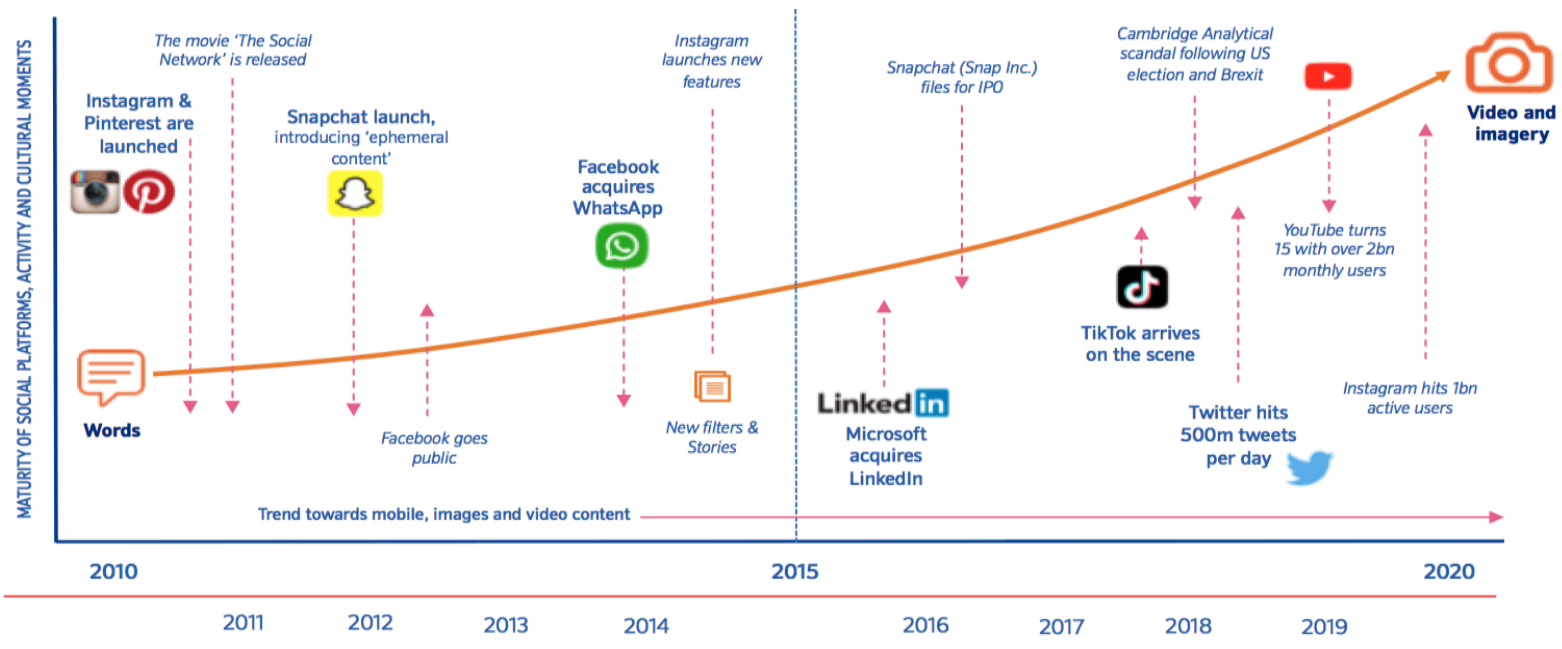

SOCIAL MEDIA FACTORS THAT INFLUENCE CONSUMER BUYING BEHAVIOUR

\section{REVIEWS FROM INFLUENCERS}

The term social influencers refers to individuals with a significant following on social media. Influencers are social media-savvy and often tag the store or brand of the products they are using, giving these institutions a broad reach over specific demographics. Regardless, if their posts are sponsored or not, their followers can be influenced in either picking up or passing on a purchase.

\section{REVIEWS FROM SOCIAL MEDIA CONNECTIONS}

Social medias initial purpose was to connect people and allow them to share information. Now, social media can be a powerful tool for users to voice their opinion on a product or brand with faster speed and broader reach. Most of consumers considering purchases based on a friends suggestions, theres no denying the influence it has on your target market.

\section{BRANDS SOCIAL MEDIA PRESENCE}

Its not enough to be selling products and services online. The brand must stand out and be recognizable amidst the sea of information available to social media users. Having a consistent and distinct voice on the chosen social media plat form plus a regularly updated feed can boost the brand image and credibility to existing followers and prospects, making conversions more likely to happen.

\section{SOCIAL MEDIA ADVERTISING}

As social media continuously reaches a wider audience, social media advertising has made it possible for hyper focused targeting and retargeting. Advertising through social media increases brand recognition and improves brand loyalty.

\section{TRENDING \& POPULAR ALGORITHMS}

Platforms like Facebook, Twitter and Instagram have moved from showing posts on their newsfeeds chronologically to displaying posts with more engagements first. Businesses are taking advantage of this algorithm by encouraging likes, comments, and shares on their content. This move can also foster conversations between companies and consumers, and influence overall brand image.

\section{OBJECTIVES \& METHODOLOGY OF THE STUDY}

The main and objectives of the study are following

1 . To study the concept of social media.

2. To analyze the impact of social media on consumer buying behavior.

3. Present study is based on secondary data sources.

4. Study awareness and knowledge levels of consumers towards organic food products

\section{LITERATURE REVIEW}

Mukhaini (2014) studied on impact of using social media on consumer buying behavior. With the objective to understand which type of products mostly purchased using social media that are mostly used by consumers in Oman. The study shows that Instagram is the most suitable social media site for the Omani consumers to buy their preferred product (fashion) online. 


\section{International Advanced Research Journal in Science, Engineering and Technology}

Vol. 8, Issue 6, June 2021

DOI: $10.17148 / I A R J S E T .2021 .8619$

Voramontri \& Klieb (2018) clears about the impact of social media on consumer behaviour and states that social media users found decision making to be easier and enjoyed the process more, when compared to those who used other information sources, i.e., T.V., Radio, Newspapers etc. Social media has enabled marketers to access and monitor consumer opinions on a continual instant basis by listening- in and participating in online conversations.

Putter (2017) concludes that an emerging focus of marketers is on the use of user generated content that is created by consumers in response to specific brands and influences the perception of other consumers. Factors that influence brand perception and intention to buy include things like views of others posted, demonstrated in social media posts.

To understand the effect of marketing by social sites on consumer buying behaviour, a study conducted by Kirti (2019) and found that social networking sites shows different variety of goods/products with new brands available in the market. They also provide information about the different brands of different products. Social media sites provide lots of comments \& feedback about the desired products. As a result, consumers get the necessary information on the different products of the different brands.

Chitranshi Verma (2018) examined the impact of social media on consumer behaviour in Indian context. She concludes that consumers want the brands to take care of them and society at large. Customers also like it when companies directly respond to them and social media makes it easier. Customers these days relying heavily on social media networks for customer support and service, so companies should make themselves visible in the digital media for rendering this support.

Rob Fitzgerald (2019) finds in his study on the impact of social media to consumer buying behaviour that consumers are $71 \%$ more likely to make a purchase based on social media referrals, 475 of purchases of youths are influenced by social media. They are also 1.6 times more likely to use digital channels to learn about new products.

\section{CONCLUSION}

The study has revealed that consumers' behaviour plays a major role in organic food products segment. The marketers of organic foods need to be innovative and dynamic to meet the changing purchase behaviour for organic food products in social media. The majority of organic food consuming respondents believed that organic food products contained no pesticides, while most of the non-organic food consuming respondents believed that organic food commodities were natural products. The main reason behind buying an organic food product was health consciousness. Though the organic food product was regarded healthy, the lack of trust on the originality of organic food product was another reason for not buying the organic food product in the study area. Hence, the firm producing and selling organic food products must find social media marketing to create trust among the consumers to improve their purchase intention. It was also found that the organic food consumers had high influence of psychological factors such as perception, attitude and purchase intention towards buying organic food products.

\section{REFERENCES}

1. Elham Al- Mukhaini (2014), The impact of social media on consumer buying behaviour, Sultan Qaboos

2. University, College of Economics \& Political Science, Information System Department, INFS 4481

3. D. Voramontri \& L. Klieb (2018),Impact of social media on consumer behaviour, international journal information \& decision sciences, vol. x, no. y, xxxx Miceal Putter (2017), Impact of social media on consumer buying intention, journal of international business research \& marketing, volume 3 , issue 1

4. Gulzar Asma \& Maqbool Misbah (2018), Impact of social media marketing on consumer buying behaviour, research review international journal of multidisciplinary, Kirti Arekar (2019), The impact of social media on the effectiveness of consumer buying behaviour for electronics goods, the electronic journal of information systems evaluation, volume 21, issue 2

5. Chitranshi Verma (2018), Impact of social media on consumer behaviour in Indian context, international journal of scientific engineering \& research (IJSER) www.connextdigital.com

6. Willer H, Lernoud J. Organic Agriculture Worldwide 2016: Current Statistics. Frick: Research Institute of Organic Agriculture (FiBL). 2016.

7. Zanoli R, Naspetti S. Consumer motivations in the purchase of organic food: a means-end approach. British food journal. 2002 Sep $1 ; 104(8): 643-53$

8. Gracia Royo A, Magistris TD. Organic food product purchase behaviour: a pilot study for urban consumers in the South of Italy

9. Gupta KB. Consumer behaviour for food products in India. In19th Annual World Symposium of the Indian Institute of Management, Bombay, India, June 2009 Jun 20 (pp. 20-21).

10. Hill H, Lynchehaun F. Organic milk: attitudes and consumption patterns. British Food Journal. 2002 Aug 1;104(7):526-42. 16. Kaur P, Singh R. Uncovering retail shopping motives of Indian youth. Young Consumers. 2007 Jun 19;8(2):128-38.

11. Lockie S. Going organic: mobilizing networks for environmentally responsible food production. CABI; 2006.

12. Www.searchenginejournal.com

13. www.google.com 